Supplement of

\title{
Composition and volatility of SOA formed from oxidation of real tree emissions compared to single VOC-systems
}

Arttu Ylisirniö et. al.,

S1. Sesquiterpene mixture and Scots pine emission description

Table S1. Identified compounds and their relative contributions to the sesquiterpene mixture, based on GC-MS analysis.

\begin{tabular}{l|r} 
Compound & Fraction \% \\
\hline cis - $\beta$-farnesene & $7.89 \pm 0.44$ \\
(E) - $\beta$-farnesene & $9.56 \pm 0.11$ \\
(Z.Z) - $\alpha$-farnesene & $8.47 \pm 0.24$ \\
(E.Z) - $\alpha$-farnesene & $7.25 \pm 0.08$ \\
cis - $\alpha$-farnesene & $6.69 \pm 0.29$ \\
trans $-\alpha$ - bisabolene & $5.46 \pm 0.38$ \\
$\beta$ - bisabolene & $9.73 \pm 0.19$ \\
trans - $\gamma$-bisabolene & $4.51 \pm 0.11$ \\
cis - $\alpha$-bisabolene & $18.31 \pm 0.64$ \\
unidentified SQT & $4.49 \pm 0.10$ \\
unidentified SQT & $3.98 \pm 0.29$ \\
unidentified SQT & $5.95 \pm 0.13$ \\
unidentified SQT & $7.73 \pm 0.11$
\end{tabular}




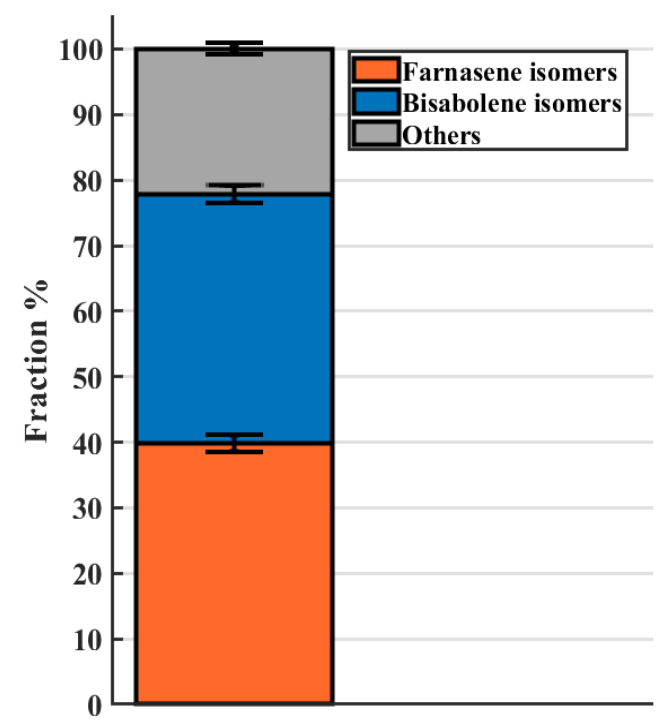

Figure S1: Graphical representation of data from Table S1, where different isomers of farnesene and bisabolene are summed up together. Unidentified compounds are summed into others class.

Table S2. Identified compounds and their relative contributions to the Scots pine emissions, based on GC-MS analysis.

\begin{tabular}{l|r|r} 
Monoterpenes & $\begin{array}{r}\text { Fraction from total } \\
\text { emission \% }\end{array}$ & $\begin{array}{r}\text { Fraction from total } \\
\text { emission \% } \\
\text { (Scots pine exp. 1) }\end{array}$ \\
\hline$\beta$-Phellandrene & $13.11 \pm 0.56$ \\
(Scots pine exp. 4)
\end{tabular}




\begin{tabular}{l|r|r}
\hline Trans- $\beta$-Farnesene & $41.17 \pm 0.58$ & $14.3 \pm 4.68$ \\
$\alpha$-Farnesene & $9.81 \pm 0.95$ & $1.83 \pm 0.73$ \\
$\alpha$-Bisabolene & $2.13 \pm 0.14$ & $0.61 \pm 0.14$ \\
aromadendrene & $0.14 \pm 0.07$ & $0.09 \pm 0.06$ \\
$\beta$-Caryophyllene & $0.06 \pm 0.04$ & $0.12 \pm 0.07$ \\
$\alpha$-Humulene & $0.06 \pm 0.03$ & $0.15 \pm 0.04$ \\
$\alpha$-Copaene & $0.06 \pm 0.01$ & $0.09 \pm 0.01$ \\
$\beta$-Elemene & $0.03 \pm 0.01$ & $0.02 \pm 0.01$ \\
Longifolene & $0.01 \pm 0.01$ & 0
\end{tabular}

\section{S2. PTR-ToF-MS calibration}

The PTR-ToF-MS was calibrated using a calibration gas standard with 8 aromatic compounds of mixing ratios $\sim 100$ ppbv in nitrogen (BOC, United Kingdom). The same gas standard was used to correct for non-ideal transmission in the instrument. Monoterpene and sesquiterpene concentrations were estimated from the Scots pine emission data using the ion signals of the protonated compounds at $\mathrm{m} / \mathrm{z} 137$ for monoterpenes and $\mathrm{m} / \mathrm{z} 205$ for sesquiterpenes, and accounting for the fragmentation of these ions by applying factors of 0.478 for monoterpenes and 0.5 for sesquiterpenes (compare (Kari et. al., 2018)).

\section{S3. FIGAERO-CIMS calibration}

The FIGAERO-CIMS mass axis was calibrated using known reagent ions and background signals, such as $I^{-} \mathrm{H}_{2} \mathrm{OI}^{-}, \mathrm{HNO}_{3} I^{-}$, $I_{2}{ }^{2}, I_{3}$. Sensitivity calibration was not performed as each observed molecule should have been identified and calibrated individually, which was not possible with the experimental setup our study is based on. We therefore mostly show

25 normalized data.

The conversion from peak desorption temperatures $T_{\max }$ to saturation vapor pressure $P_{\text {sat }}$ and from there to saturation vapor concentration $C^{*}$ was performed using a modified calibration method based on Bannan et al. (2018), using a series of polyethelyne glycols (PEG) as reference compounds. Details of that modification will be published shortly in a separate publication. Calibration was done by fitting eq. S1 to measured values of $T_{\max }$ and literature-based values of $P_{\text {sat }}$. for the PEGs:

$P_{\text {sat }}=\exp \left(b T_{\max }+a\right)$

where $a$ and $b$ are fitting coefficients. These coefficients were the following for FIGAERO inlets 1 and 2:

35 FIGAERO 1: $a=-1.431, b=-0.207$

FIGAERO 2: $a=-3.929, b=-0.132$. 

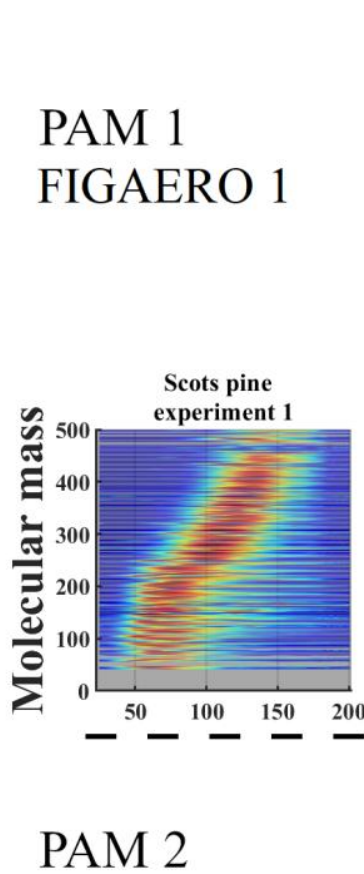
FIGAERO 2
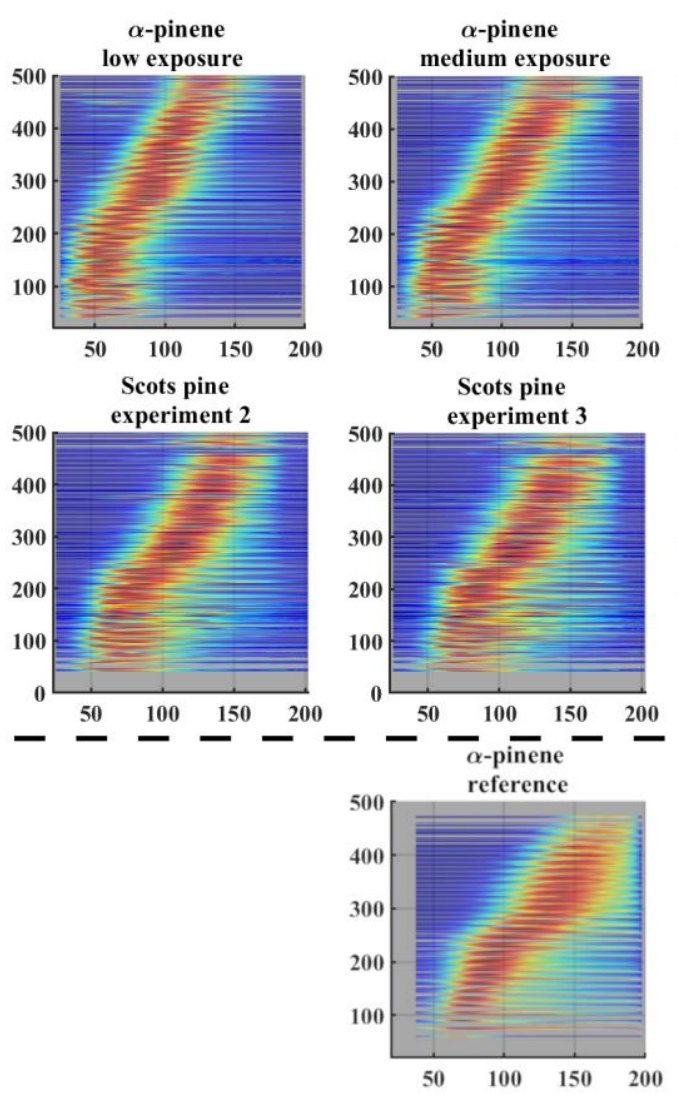

\section{Desorption temperature $\left({ }^{\circ} \mathrm{C}\right)$}

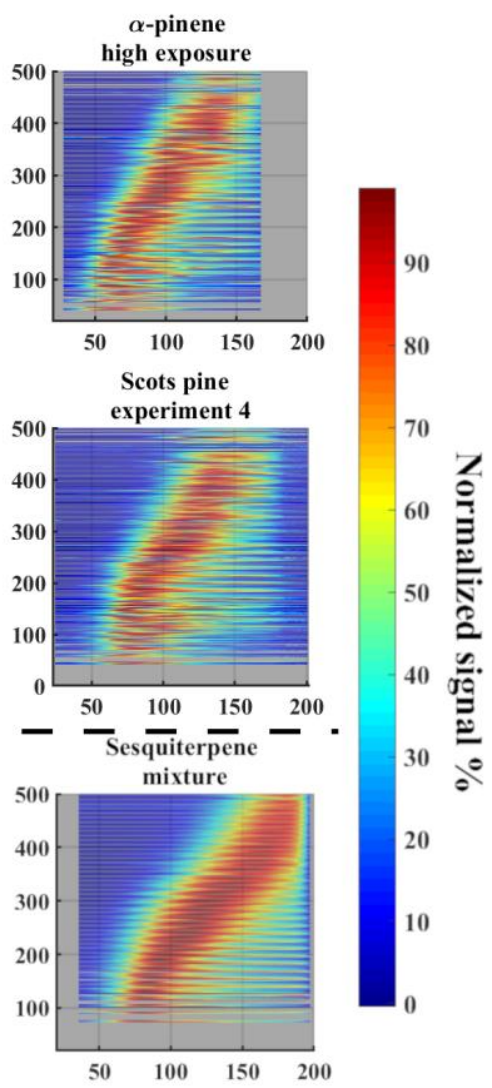

Figure S2: Individual ions' thermograms from each experiment, each depicted as a separate two-dimensional, colored plot. The xaxes show desorption temperature; y-axes nominal (integer) ion mass. For clarity, signals have been summed up for each nominal mass, and colors show the intensity of said nominal mass normalized to the respective thermogram's maximum signal. Top row: $\alpha$ pinene experiments (cf. Fig. 5a). Middle row: Scots pine experiments (cf. Fig. 5b). Bottom row: experiments using PAM 2 (sesquiterpene mixture and reference $\alpha$-pinene experiment; cf. Fig. 5c).

Figure S2 reveals that the $T_{\max }$ value of detected ions are in general dependent on their molecular weight, as is expected. However, this dependence tends to disappear for ions corresponding to compounds with molecular weights less than around $150 \mathrm{Da}$, and their $T_{\max }$ tend to fall inside the same range. On the one hand, that is likely a form of observational bias, as at 50 this lower molecular weight range, only relatively lower-volatility compounds would partition into the particle phase. On the other hand, as mentioned above, we can expect at least some compounds with lower molecular weights to be products of thermal decomposition of larger compounds. More apparent signatures of thermal decomposition are visible as well: thermograms peaking at clearly higher temperatures than expected by the respective molecular weight, and thermograms 
substantially extending towards higher temperatures (tailing). Both of those signatures have also been extensively observed 55 also in previous studies (Wang et al., 2016, D'Ambro et al., 2017; Lopez-Hilfiker et al., 2014; Lopez-Hilfiker et al., 2015; Lopez-Hilfiker et al., 2016; Schobesberger et al., 2018).

The top row of Fig. S2 shows that not only do the sum thermograms for the $\alpha$-pinene experiments shift to higher desorption temperatures with increasing oxidation exposure, but the shift is essentially seen throughout the spectrum of individual thermograms (cf. Fig. 5). In addition, an increasing role of thermal decomposition is apparent, especially through increasing tailing of the thermograms. In the same manner, $T_{\max }$ values are increased throughout the spectrum when comparing the reference $\alpha$-pinene to the sesquiterpene mixture experiment (bottom row Fig. S2), with notable contributions of decomposition processes in both cases. In line with these observations, and those in Figs. 4-5, the plots obtained from the Scots pine experiments (middle row Fig. S2) broadly appear as expected: as in-between cases between the $\alpha$-pinene and the

65 sesquiterpene results. As in Fig. 5, Scots pine experiment 4 features the highest $T_{\max }$ values, and also somewhat larger apparent contributions by thermal decomposition products. But overall, the similarities to the other Scots pine experiments (especially experiment 3) predominate (cf. Fig. 4), in spite of the much higher contribution of monoterpenes than in experiments 1-3.

\section{References:}

70 Ambro, E. L. D., Lee, B. H., Liu, J., Shilling, J. E., Gaston, C. J., Lopez-hilfiker, F. D., Schobesberger, S., Zaveri, R. A., Mohr, C., Lutz, A., Zhang, Z., Gold, A., Surratt, J. D., Rivera-rios, J. C., Keutsch, F. N. and Thornton, J. A.: Molecular composition and volatility of isoprene photochemical oxidation secondary organic aerosol under low- and high-NO $\mathrm{x}$ conditions, , 159-174, doi:10.5194/acp-17-159-2017, 2017.

Bannan, T. J., Le Breton, M., Priestley, M., Worrall, S. D., Bacak, A., Marsden, N. A., Merha, A., Hammes, J., Hallquist,

75 M., Alfarra, M. R., Krieger, U. K., Reid, J. P., Jayne, J., Robinson, W., Mcfiggans, G., Coe, H., Percival, C. J. and Topping, D.: A method for extracting calibrated volatility information from the FIGAERO-HR-ToF-CIMS and its application to chamber and field studies, , (August), 1-12, doi:10.5194/amt-2018-255, 2018.

Kari, E., Miettinen, P., Yli-Pirilä, P., Virtanen, A. and Faiola, C. L.: PTR-ToF-MS product ion distributions and humiditydependence of biogenic volatile organic compounds, Int. J. Mass Spectrom., 430, 87-97, doi:10.1016/j.ijms.2018.05.003,

802018

Lopez-Hilfiker, F. D., Mohr, C., Ehn, M., Rubach, F., Kleist, E., Wildt, J., Mentel, T. F., Lutz, A., Hallquist, M., Worsnop, D. and Thornton, J. A.: A novel method for online analysis of gas and particle composition: Description and evaluation of a filter inlet for gases and AEROsols (FIGAERO), Atmos. Meas. Tech., 7(4), 983-1001, doi:10.5194/amt-7-983-2014, 2014.

Lopez-Hilfiker, F. D., Mohr, C., Ehn, M., Rubach, F., Kleist, E., Wildt, J., Mentel, T. F. and Carrasquillo, A. J.: Phase

85 partitioning and volatility of secondary organic aerosol components formed from $\alpha$-pinene ozonolysis and $\mathrm{OH}$ oxidation: the importance of accretion products and other low volatility, Atmos. Chem. Phys., 7765-7776, doi:10.5194/acp-15-77652015, 2015.

Lopez-Hilfiker, F. D., Iyer, S., Mohr, C., Lee, B. H., D’ambro, E. L., Kurtén, T. and Thornton, J. A.: Constraining the sensitivity of iodide adduct chemical ionization mass spectrometry to multifunctional organic molecules using the collision

90 limit and thermodynamic stability of iodide ion adducts, Atmos. Meas. Tech., 9(4), 1505-1512, doi:10.5194/amt-9-15052016, 2016.

Schobesberger, S., D’Ambro, E. L., Lopez-Hilfiker, F. D., Mohr, C. and Thornton, J. A.: A model framework to retrieve thermodynamic and kinetic properties of organic aerosol from composition-resolved thermal desorption measurements, Atmos. Chem. Phys., 18(20), 14757-14785, doi:10.5194/acp-18-14757-2018, 2018. 
95 Wang, M., Yao, L., Zheng, J., Wang, X., Chen, J., Yang, X., Worsnop, D. R., Donahue, N. M. and Wang, L.: Reactions of Atmospheric Particulate Stabilized Criegee Intermediates Lead to High-Molecular-Weight Aerosol Components, , doi:10.1021/acs.est.6b02114, 2016. 